\title{
Estimation and use materials of the airily-depressed surveys on the coal mines of Ukraine
}

\author{
Tetiana Bunko, ${ }^{1, *}$, Maksym Shyshov ${ }^{2}$, Vadym Myroshnychenko ${ }^{2}$, Ivan Kokoulin ${ }^{1}$, and \\ Mykhailo Dudnyk ${ }^{1}$ \\ ${ }^{1}$ Institute of Geotechnical Mechanics named by N. Poljakov of National Academy of Sciences of \\ Ukraine, 49005, Dnipro, Simferopolska Str., 2a, Ukraine \\ ${ }^{2}$ DTEK, 01032, Kyiv, Lva Tolstoho Str., 57, Ukraine
}

\begin{abstract}
Need to improve the methodological and technical means of obtaining, adjusting and updating the results of the airly-depressed surveys (ADS). With this purpose, identified issues that do not respond modern tasks of the ADS concerning the control of the aerological condition of coal mines. Methods of structural and parametric identification of the mine ventilation network are developed. It is proposed to replace obsolete control devices of aerodynamic parameters more modern, developed by Institute of Geotechnical Mechanics named by N. Poljakov of National Academy of Sciences of Ukraine, devices: anemometer portable mine APR-2, micromanometer differential mine MDR-6, the converter difference of pressure PRD-1. It is proposed a new approach to actualization of information, consisting in the joint of measurements by stationary and portable control devices. Methods of structural-parametric identification and measuring instruments of the aerodynamic parameters of a new technical level offered for the first time. Use of the proposed methods and technical means processing the results of the ADS will improve the quality of aerodynamic information received.
\end{abstract}

\section{Introduction}

In the conditions of intensive development of mining works, the ventilation networks of coal mines become more extensive and branched, as a result of which the complication the task of correct forecasting of their ventilation become complicated. Calculations of airdistribution in the mine ventilation network (MVN) is not possible without the use of modern computer technique, and so - the creation of a mathematical model MVN for ventilation calculations.

For creation of correct mathematical model of MVN it is necessary to solve several interconnection tasks:

a) create a calculation scheme of the MVN, that is to draw on paper in conditional form an aggregate of mine workings (in the future we shall call them the branches of the

\footnotetext{
*Corresponding author: bunko2017@ukr.net
} 
network), ventilation constructions and main fans (MF);

b) to determine on it the places of the necessary measurements (basis) aero- (if necessary - and gas-dynamic) parameters, the totality of which will provide an exhaustive representation about aerodynamic state of the MVN;

c) to carry out an experimental measurements of aerodynamic parameters in mining workings and their geometric parameters;

d) combining the results of works a) - c), to create the mathematical model of MVN;

e) to assess the structural and parametric adequacy of the received mathematical model of MVN and its real analog, which in general is necessary, and its degree - sufficient condition for use of the obtained mathematical model in the calculations of air-distribution in the MVN, and in the future - and during the MVN control in normal and emergency conditions.

Works of items a) - c) in production conditions are carried out in the process of conducting of airly-depressed surveys (ADS) be the units of the State paramilitary mine rescue service (SPMRS), and in the regulated period between their carrying out at the mine (three years) - employees of the district of ventilation and safety technique (VST) of the mine. The results obtained require further processing, which shown by methods of structural and parametric identification, a large part of which was created at the Institute of Geotechnical Mechanics named by N. Poljakov of National Academy of Sciences of Ukraine (IGTM NAS of Ukraine). Attaining during the creation of mathematical model of MVN the necessary level of its adequacy to the real ventilation network, can be obtained an information base for control by mine ventilation.

Carrying out of the ADS of coal mine is an integral part provision of the life of mine. Therefore, to regulate its conducting exists and periodically updated the relevant normative document; last him version is the Guidance normative document of the Ministry of Fuel and Energy of Ukraine "Depression and gas surveys in coal mines. Methods of conducting. Instruction". In fact, it regulates only methods of the works of item c), leaving the decision of the previous of items a) - c) in production conditions are carried out in the process items a) - b) and the subsequent items d) - e) works at the discretion of the management and personnel of the mine.

Therefore, there is now many approaches to the creation of the mathematical model of MVN, and the program realization of the decision of separate its tasks are carried out by several software complexes developed IGTM NAS of Ukraine, Naukovo-Doslidnyi Instytut Hirnychoriatuvalnoi Spravy ta Pozhezhnoi Bezpeky «Respirator», Donetsk National Technical University and others.

The general regulated approach to the creation of the mathematical model of MVN does not exist at all, and even a simplified document of 2005 year, which partially implements the decision of these problems, is outdated and not tells modern realities. Therefore, the purpose of the publication is to prepare a new version of the document, which would regulate the main stages of the creation of the mathematical model of MVN and took into account changes that have recently occurred in methodological approaches to obtaining information concerning the aerodynamic state of the MVN, and the characterization of the methods of solution scientific and practical tasks which arise in this case.

\section{Research strategy}

The research was based on the fact that the general approach to the use of results of the ADS remain unchanged, and correct decision of separate her tasks. Therefore, the research is organized as follows (Fig. 1).

From Figure 1 it can be seen that, as a result of the definition of issues missing in the old methods of conducting and processing the materials of the ADS, 12 major allocated, 
need as the improvement of existing methods (blocks $1,5,6,7,11,12$ ), and the search of new solutions (remaining blocks). Identification of issues that do not correspond to the current tasks of the ADS regarding
the aerological condition of coal mines

\begin{tabular}{|c|c|c|c|c|c|c|c|}
\hline 1 & \multicolumn{2}{|c|}{ Improvement of the graphic editor for the construction calculation schemes of } \\
ventilation
\end{tabular}

5 Correction of the principles measurement of aerodynamic parameters: air quantity electronic anemometer APR-2, pressure change - converter difference of pressure PRD-1 or micromanometer MDR-6

\begin{tabular}{|c|c|}
\hline 6 & $\begin{array}{l}\text { Correction of the methods of conducting the ADS by the complexing of the three } \\
\text { existing methods, taking into account the assessment of the joint work of the MF }\end{array}$ \\
\hline \multicolumn{2}{|r|}{$\downarrow$} \\
\hline 7 & $\begin{array}{l}\text { Correction of the method of measuring the depression of ventilation constructions } \\
\text { by the micromanometer MDR- } 6\end{array}$ \\
\hline \multicolumn{2}{|r|}{$\downarrow$} \\
\hline 8 & $\begin{array}{l}\text { Actualization of intervals of partial measurements of aerodynamic parameters of } \\
\text { MVN }\end{array}$ \\
\hline \multicolumn{2}{|r|}{$\downarrow$} \\
\hline 9 & $\begin{array}{l}\text { Improvement of the methods of routing control of aerodynamic parameters and the } \\
\text { integration of their measurements by stationary and portable measuring instruments }\end{array}$ \\
\hline \multicolumn{2}{|r|}{$\downarrow$} \\
\hline 10 & $\begin{array}{l}\text { Creation of estimated dependencies number of necessary portable instruments of } \\
\text { aerodynamic control from the dimension of the ventilation network }\end{array}$ \\
\hline \multicolumn{2}{|r|}{$\nabla$} \\
\hline 11 & Aerodynamic monitoring of ventilation during emergencies \\
\hline \multicolumn{2}{|r|}{$\downarrow$} \\
\hline 12 & $\begin{array}{l}\text { Estimation possibilities of using computer technology for the calculation and } \\
\text { control of ventilation systems, developed by the IGTM NAS of Ukraine, and the } \\
\text { need to develop additional software }\end{array}$ \\
\hline
\end{tabular}

Fig. 1. Structural scheme perfection of conducting and processing results of ADS. 


\section{Results and discussion}

1. Up to the present time formation of the calculation schemes of ventilation conducted manual, and the graphic editor, in the prevalence number of cases, uses for visualization (building an electronic version of the scheme based on the drown), and improvement of perception. In addition, the distinction of the ventilation system is that it is not a collection of only really existing workings, but also contains uncertain areas (parts of the produced lava space, the zone of collapse).

Many problems automation creation of calculation scheme remained out of sight, or were not yet resolved as a result of complexity (construction of a volumetric scheme, rotation of the scheme around coordinates axes, allocation part of the scheme by separating the graph of the network, etc.). But even manually build a calculation scheme is quite difficult.

The scheme which is used as the primary for its construction, is a surveyor two-line mine scheme. It gives an impression, if not a spatial representation of mines workings, then at least about the shape projection of the horizon or panel on the horizontal plane. And even with the real, in the adopted scale, the length of workings, and their mutual arrangement.

But this scheme has significant disadvantages, in particular: presence the number of sites whose aerodynamic parameters can not be determined in consequent of inaccessibility for measurements; the presence of parts that do not participate in ventilation (deadlocks, workings of technological destination, where in consequence of peoples the amount of air does not require regular control, etc.).

On the surveyor scheme they are not present, but certain participation in the process of ventilation they are assume. Therefore the construction of calculation scheme is not a technical work, but an art, which is impossible to completely formalize.

As a result of the inherent to the compiler peculiarities of thinking scheme main's be universal and will require of some conditional simplifications.

For facilitate of such actions are used at the stage construction of a calculation scheme two sets of criteria and methods, namely: method of the assessment adequacy of the underlying design scheme its real analogy (in the confines of information provided by the calculation scheme, and own perception about the real object by the consumer) and methods of structural identification of MVN.

2. Method for assessing of structural adequacy are described in detail in [1]. Shortly an aggregate criteria of structural adequacy can be characterized as follows: how much, in qualitative and quantitative terms, the real MVN coincide with the modeling analogue (number, relative position of elements, their connection, etc.), and on an accepted scale, if there is a need for it, - as soon as possible the geometric characteristics of these are relatively accurately displayed.

If networks are considered as structurally adequate with a given degree of accuracy - it is necessary to check their parametric adequacy by the method given in the source [1]. Since the basic aerodynamic parameters elements of MVN are debit of air and depression of workings, parametric criteria adequacy is focused on minimizing of deviations of values for networks that analysing on adequacy, precisely for these parameters.

The task of structural identification of the MVN with indeterminate zones lies in establishing the correspondence between the elements of the real MVN (which assign by the graph $G(X, U)$, where $X$ - quantity of modes, dimension of which is $m, U$ - quantity of branches, dimension of which is $n$ ) and its MM (which assign by the graph $G_{M}\left(X_{M}, U_{M}\right)$, where $X_{M}, U_{M}$ - quantity of modeling modes and branches with dimension $m$ and $n$ respectively) by way of identification of basic aerodynamic connections between its elements and definition a plurality of main and additional air users. 
Method decision task of structural identification for the case of MVN with non-defined structure, is shown on Figure 2.

Thus, the task of structural identification is to maximize the small of deviation in any of the nodes of real and simulated networks, not exceeded the value of the criterion of adequacy associated with the measurements of air debit $a d\left(G_{M}^{Q(i, j)}\right)$ with condition $\min \left\{\operatorname{dim} G_{M}^{Q(i, j)}\right\}$ - minimization of dimensional and reciprocal criteria of network. $Q(i, j)-$ debit of air in the working $(i, j), \mathrm{m}^{3} / \mathrm{s}$.

The task of parametrical identification of the MVN with indefinite aerodynamic parameters are to assess of probability of the air values of air flow at all network areas and pressure in all nodes of the network due to changes to only some of these variables.

As a result of solving the problem by the calculated or experimental data, determined the values of aerodynamic resistances, distribution of depressions and the air debits in all MVN workings, which satisfying the network laws.

\begin{tabular}{|c|c|}
\hline 1 & Assignment of the initial network $G(X, U)$ and the allocation of $U_{\text {const }}$, respectively \\
\hline \multicolumn{2}{|r|}{$\nabla$} \\
\hline 2 & $\begin{array}{l}\text { Verification of the coincidence of the main route "object of ventilation - MF" on the } \\
\text { simulated and initial networks according to the criterion of structural similarity }\end{array}$ \\
\hline \multicolumn{2}{|r|}{$\nabla$} \\
\hline 3 & Allocation zones of uncertainty $M_{k}\left(X^{M}{ }_{k}, U^{M}{ }_{k}\right)$ \\
\hline \multicolumn{2}{|r|}{$\downarrow$} \\
\hline 4 & $\begin{array}{l}\text { Identification of modes } \Delta q_{l}=\sum_{(i, j) \subset U_{l}} Q(i, j), \quad l=1, \ldots, m ;\left|\Delta q_{l}\right| \geq \xi, \quad l=1, \ldots, m^{\prime}, \\
\text { where } \Delta q_{l} \text { is the nonconventional flow of air in mode } l, \mathrm{~m}^{3} / \mathrm{s} ; \xi \text { - required accuracy } \\
\text { of air distribution in mode } l ; m^{\prime}-\text { number of modes in violation of the first law of } \\
\text { networks }\end{array}$ \\
\hline \multicolumn{2}{|r|}{$\downarrow$} \\
\hline 5 & 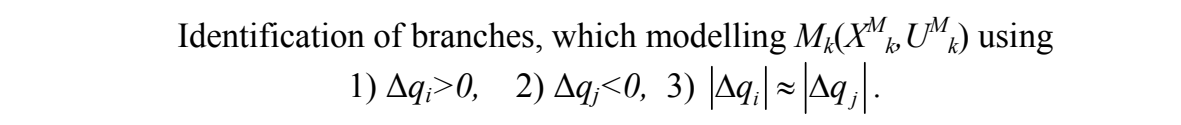 \\
\hline \multicolumn{2}{|r|}{$\downarrow$} \\
\hline 6 & Identification of criteria $a d\left(G_{M}^{Q(i, j)}\right)=\max \left\{\sum_{(i, j) \subset U_{l}} Q(i, j)\right\}, \quad l=1, \ldots, m^{\prime}$ \\
\hline
\end{tabular}

Fig. 2. Algorithm for structural identification of MVN.

After completion of this stage it is necessary to solve a problem of parametrical identification.

The mathematical formulation of the task identifying of the aerodynamic parameters of the MVN [1] consists in minimizing of functional:

$$
F=\sum_{(i, j) \subset U}\left[\frac{1}{\left(\delta_{(i, j)}^{q}\right)^{2}}\left(Q(i, j)-Q^{*}(i, j)\right)^{2}+\frac{1}{\left(\delta_{(i, j)}^{h}\right)^{2}}\left(H(i, j)-H^{*}(i, j)\right)^{2}\right] \rightarrow \min
$$


with restrictions

$$
\begin{aligned}
& \sum_{(i, j) \subset U_{l}} Q(i, j)=0, \quad l=1, \ldots, m \\
& \sum_{(i, j) \subset U_{\mu}}\left((\operatorname{sign} Q(i, j)) R(i, j) Q^{2}(i, j) \pm h_{e}\right)-\sum_{(i, j) \subset\left(U_{\mu} \cap U_{b}\right)} H(i, j)=0, \quad \mu=1, \ldots, m-n+1 \\
& H(i, j)=a(i, j)-b(i, j) Q^{2}(i, j), \quad(i, j) \subset U_{b} \\
& R(i, j)=\frac{\alpha(i, j) \cdot P(i, j) \cdot L(i, j)}{[S(i, j)]^{3}}, \quad(i, j) \subset U \backslash U_{b} \\
& Q(i, j)=S(i, j) \cdot V(i, j), \quad(i, j) \subset U \backslash U_{b} \\
& R^{\min }(i, j) \leq R(i, j) \leq R^{\max }(i, j), \quad(i, j) \subset U \backslash U_{b} \\
& Q^{\min }(i, j) \leq Q(i, j) \leq Q^{\max }(i, j), \quad(i, j) \subset U \\
& H^{\min }(i, j) \leq H(i, j) \leq H^{\max }(i, j), \quad(i, j) \subset U
\end{aligned}
$$

where $U-$ a quantity of branches of MVN; $U_{l}-$ a quantity of branches incident to the first node; $U_{\mu}-$ a quantity of branches that belong to the $\mu$ independent contour; $U_{b}$ is the quantity of MF; $h_{e}$ is the value of the natural draft acting in $\mu$ independent contour; $L(i, j)-$ length of working, m; $S(i, j)$ is the area cross-section of the working, $\mathrm{m}^{2} ; Q(i, j), Q^{\min }(i, j)$, $Q^{\max }(i, j)$ - respectively debit of air in the working, its minimum and maximum permissible values, $\mathrm{m}^{3} / \mathrm{s} ; H(i, j), H^{\min }(i, j), H^{\max }(i, j)$ respectively depression of working, its minimum and maximum permissible values, $\mathrm{Pa} ; R(i, j), R^{\min }(i, j), R^{\max }(i, j)$ - respectively resistance of the working, its minimum and maximum permissible values, $\mathrm{Pa} \cdot \mathrm{s}^{2} / \mathrm{m}^{6} ; \alpha(i, j)$ - coefficient of resistance of the working, $\mathrm{Pa} \cdot \mathrm{s}^{2} / \mathrm{m}^{2} ; \delta^{q}(i, j), \delta^{h}(i, j)$ - respectively the value of the probability of the problem of quantities $Q(i, j), H(i, j)$ in working. Its dimensions are $\mathrm{m}^{3} / \mathrm{s}$ and Pa respectively ; $a(i, j), b(i, j)$ - coefficients of the approximation of the characteristics of the MF, $\mathrm{Pa}$ and $\mathrm{Pa} \cdot \mathrm{s}^{2} / \mathrm{m}^{6}$ respectively; $Q^{*}(i, j), H^{*}(i, j)$ - measured values of air debit and depression of mining workings respectively; $h_{e}$ - depression of natural draught; $V(i, j)$ - rate of air motion in working, $\mathrm{m} / \mathrm{s} ; P(i, j)$ - perimeter of working, $\mathrm{m}$.

Investigation of necessary and sufficient conditions for the existence of a functional minimum (1) under restrictions (2) and (3) showed that the function of the goal (1) is protuberant, because is the sum of protuberant functions of the form

$$
\frac{1}{\left(\delta_{(i, j)}^{q}\right)^{2}}\left(Q(i, j)-Q^{*}(i, j)\right)^{2} \quad \text { and } \frac{1}{\left(\delta_{(i, j)}^{h}\right)^{2}}\left(H(i, j)-H^{*}(i, j)\right)
$$

i.e. the function has a single extremum.

Formulation of the task of identifying the aerodynamic parameters of the MVN in conditions incomplete and insufficiently reliable information should be supplemented by bilateral constraints on variables (6) - (9).

In this case it is assumed that according to the calculated formulas and experimental dependences of the change in resistance, you can get an upper bound and the lower boundary of the change of the aerodynamic parameters of the MVN.

In the formulation of the problem $P(i, j)$ - quality characteristic state of working is taken into account for the first time. For this the quantity of workings is divided into 3 groups 
depending the condition of working: I - well (workings without significant deformation); II - satisfactory (working with partially deformed fastening); III - bad (accidentally deformed workings, or with a significant amount of breed and equipment). A quantitative estimate of the resistance of these workings will be determined by the formula (5). A more detailed qualitative description of workings and taking into account it during calculation of the MVN is described in [2]. The main stages of the method identifying of uncertain aerodynamic parameters of the CFM are as follows (Fig. 3).

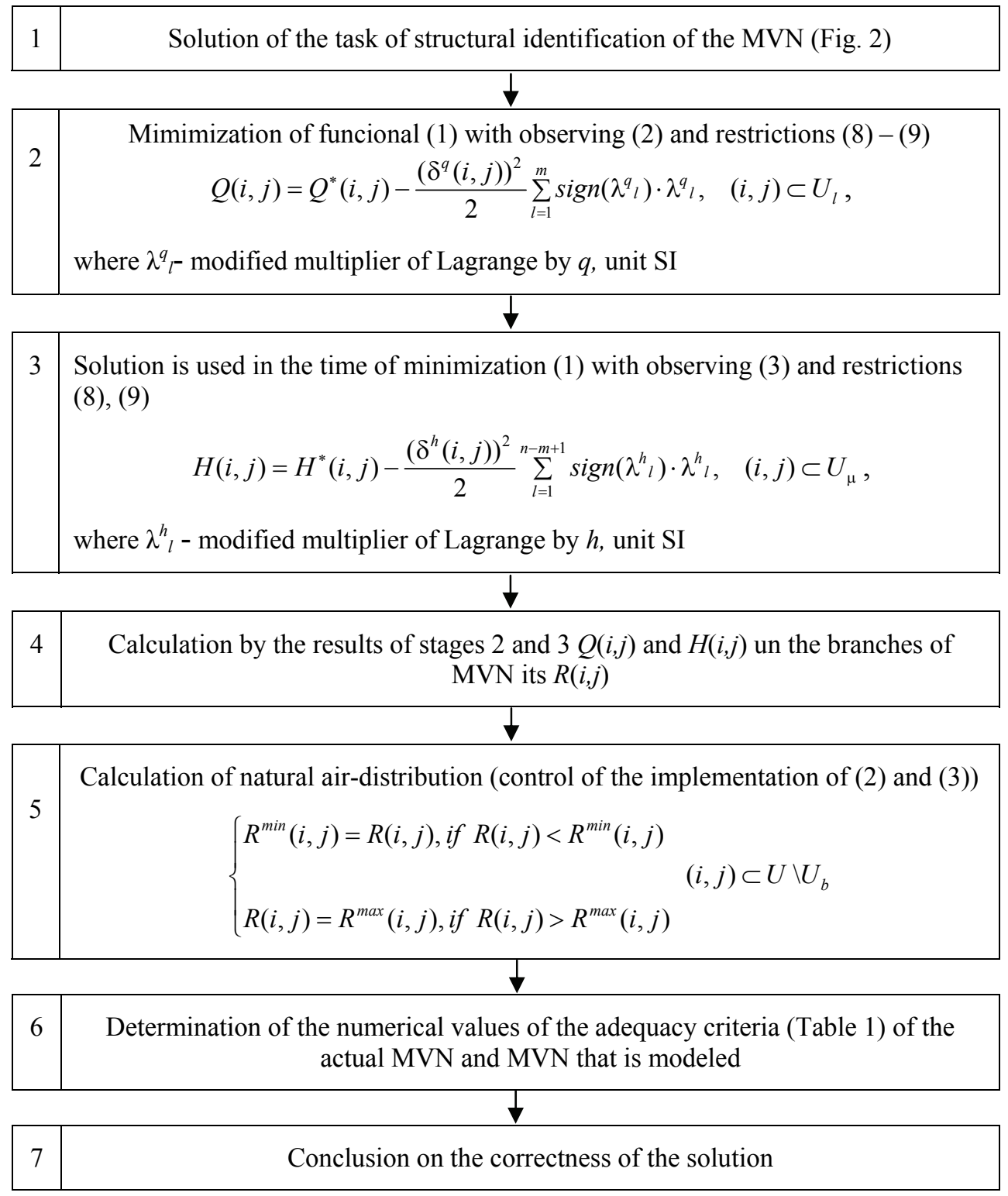

Fig. 3. Algorithm of parametrical identification of the MVN.

Thus, the tasks of blocks $2-4$ (Fig. 1), which have not been used before, during the processing of the results of the airly-depressed surveys, are solved. 
3. Measurement of aerodynamic parameters was carried out to the present time by equipment of obsolete technical level - anemometers ASO-3, MS-13 and micromanometer with a rubber tube.

In addition to the complexity of using this base did not provide sufficient accuracy of measurements.

The results forcedly wrote in the digital expression of units of the scale of device with the subsequent conversion into physical units. They replaced the new domestic development devices. The main certificated means of control the role of speed (and, then, the debit) of air in mine workings of mines not only Ukraine, as well as CIS countries, is a anemometer portable mine APR-2 [1], which was developed by IGTM NAS of Ukraine specially for mines, and the serial issue of which was mastered in 2001 (Fig. 4).

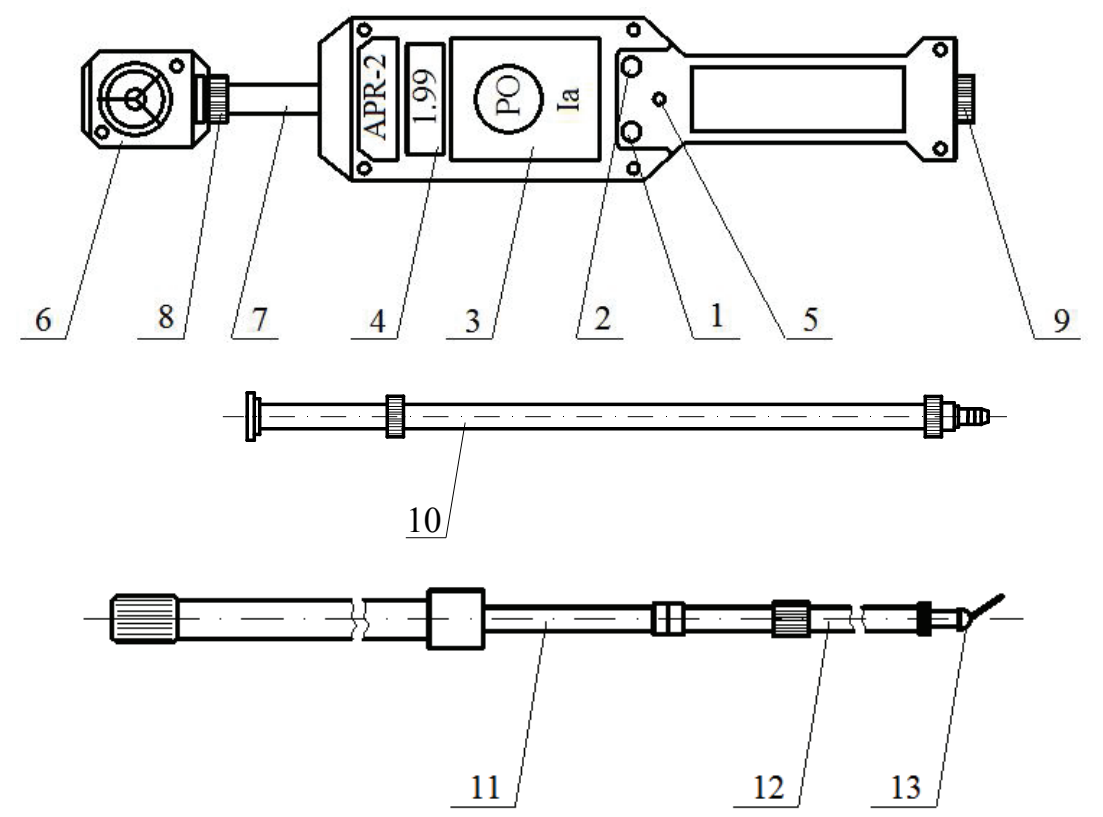

Fig. 4. Modern anemometer APR-2 complete with one-lane $0.3 \mathrm{~m}$ and iterative $3 \mathrm{~m}$ extending: 1 - switching button with fixation; 2 - control button without fixation; 3 - measuring bloc; 4 - indicator; 5 - output of the control point; 6 - primary converter; 7 - telescopic lengthening; 8 - union nut; 9 - screw; 10 - one-way bar lengthening; 11, 12 - telescopic sections of multi-link lengthening; 13 - hinge.

Our institute has released three modifications of APR-2, which greatly improved its technical and metrological characteristics. New solutions are protected by Ukrainian patents No 102727 and No 108532. The winged anemometer APR-2 differs from analogous devices for this purpose with high reliability, long and convenient operation in mine conditions, as well as better accuracy of metrological characteristics in a wide range of measurements from 0.15 to $20.0 \mathrm{~m} / \mathrm{s}$ with a maximum speed of $42 \mathrm{~m} / \mathrm{s}$ and the definition of air flow in mining structures with a flow cross section from 1 to $50 \mathrm{~m}^{2}$. Thus, since 1992 , an anemometer APR-2, which replaced the morally and physically obsolete ASO-3 and MS-13 anemometers, remains the main modern means of measuring the speed and flow of air in mines of Ukraine and CIS countries.

For accurate measurement of pressure difference and depression of extended objects as well relative humidity of air and a temperature in the workings of coal mines a differential mine micromanometer MDR-6 [1] is used (Fig. 5). 


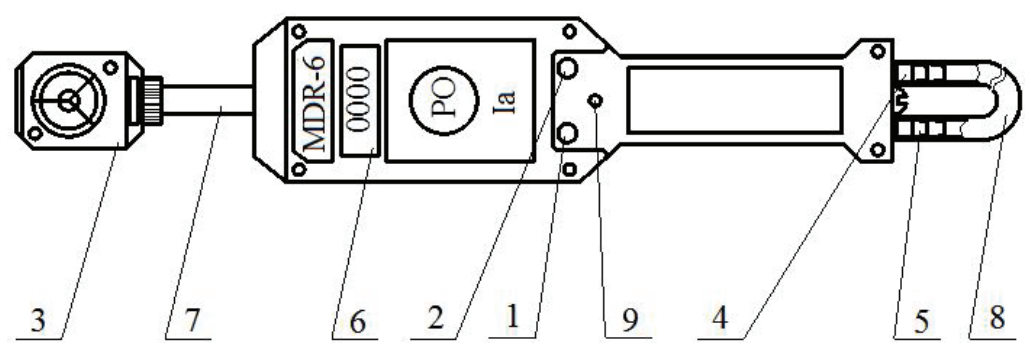

Fig. 5. Micromanometer differential mine MDR-6: 1 - button to switch to the mode of measurement of pressure differences; 2 - the power button in the mode measurements of temperature and air humidity; 3 - remote sensor of temperature and humidity of the environment; 4 and 5 - pressure pipes; 6 - digital indicator; 7 - telescopic lengthening; 8 - preventive tube; 9 - checkpoint.

This is the latest development of IGTM NAS of Ukraine. On the way of measuring the difference in air pressure we obtained Patents of Ukraine No 102288 and No 102288. Since 2018, we have mastered the release of a device that differs from the best world analogues of this purpose with more accurate characteristics of pressure measurement. The State Center for Certification and Standardization of Ukraine acknowledged that the micromanometer MDR-6 measuring the difference in pressure in the range from 0 to $6000 \mathrm{~Pa}$ with an error of not more than $\pm(2+0.002 d P)$, where $d P$ is the measured pressure drop.

The devices are equipped with processors that convert the performance of the devices directly in the system unit of measurement with the display on the device. Used one more development of the IGTM NAS of Ukraine - the converter of pressure difference PRD-1, earlier model of micromanometer MDR-6, - in combination with APR-2 [3] (Fig. 6, 7). The converter allows to measure the pressure drop at the ventilation structures (Fig. 8) and in the degassing pipelines (Fig. 9).

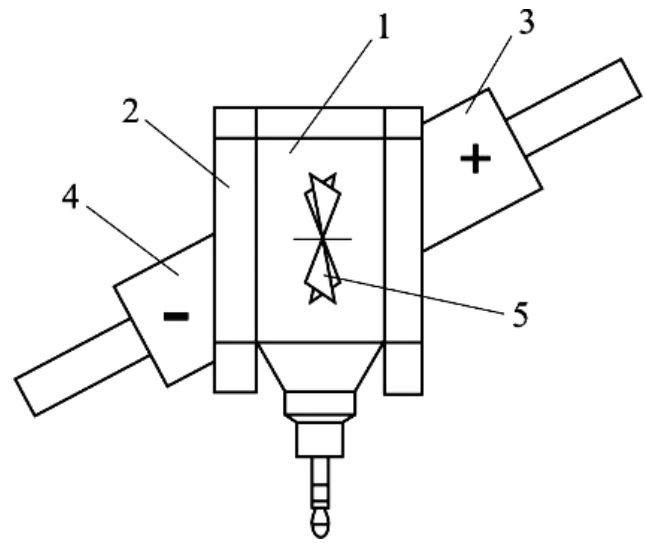

Fig. 6. Primary pressure difference converter: 1 - the primary converter of the air velocity of the anemometer APR-2; 2 - lid; 3 - high-pressure nozzle; 4 - low pressure nozzle; 5 -impeller.

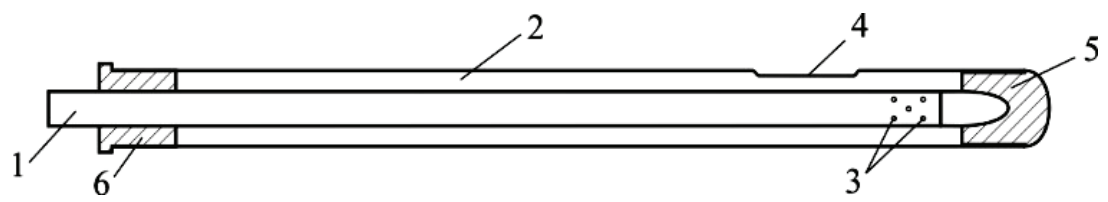

Fig. 7. Static probe to aerodynamic differential pressure converter: 1 - measuring tube; 2 - protective tube; 3 - measuring holes of the measuring tube; 4 - the entrance hole of the protective tube; 5 - stopper; 6 - plug-stopper. 


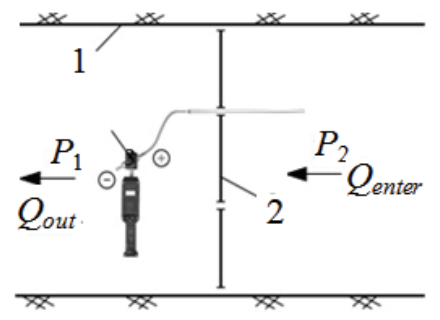

a)

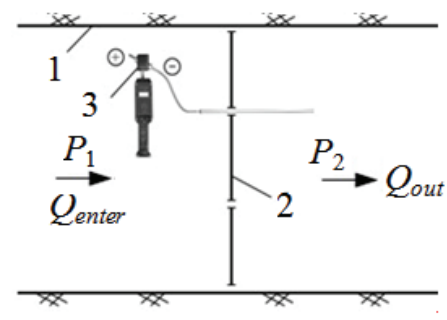

b)

Fig. 8. Measurement of pressure drop on the ventilation structure, when the observer is near the ventilation structure from the low a) and high b) pressure: 1 - mine working; 2 - ventilation structure; 3 - pressure difference converter.

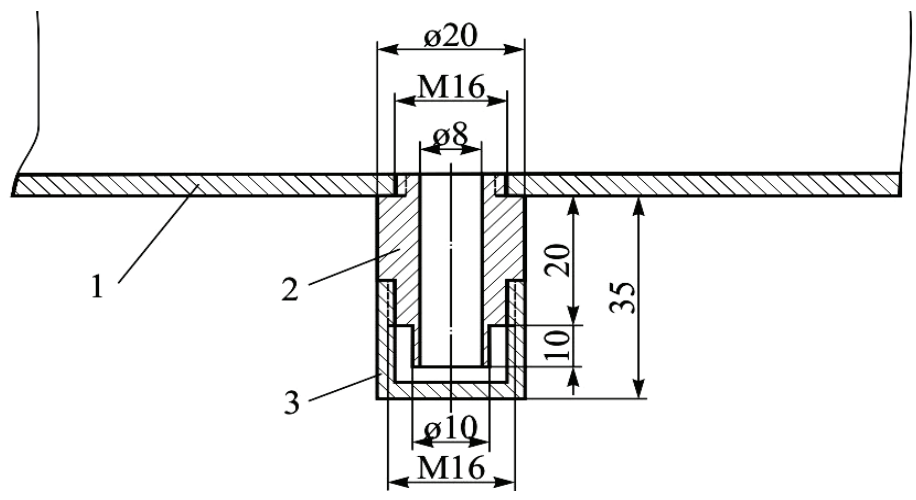

Fig. 9. Device for connect: 1 - pipeline; 2 - carbine; 3 - protective hubcap.

4. Such adjustment is carried out by Ventilation and Safety Technics District of Coal Mines, by steady (daily) control by the mining master of the district, which, moving established routes, conduct measurements of aerodynamic parameters of mine workings with portable control devices. Monitoring routes there are no constant, and adjusted by the head of the VTS district in accordance with current needs.

On the other hand, many Ukrainian mines are equipped with unified telecommunication automated dispatch control and direction systems of mining machines and technological complexes (UTAS) [4]. One of its functions is a control of the aerodynamic state of the workings of MVN, with the aim of which the system includes a complex of air velocity sensors TX1322 (or TX1322C (numerical)) and a complex of pressure sensors TX6101. Of course, that control is not the main function of UTAS, and the number of such sensors is confined, but their available basis allows you to get information about the aerodynamic state of the main control points and to transfer its to the mine dispatcher without additional interference. Thus, there is an opportunity to organize joint control of the aerodynamic parameters of the MVN elements, unconditionally whose advantages are the following.

First, such joint control will reduce the necessary measurements and reduction of the necessary points of routing control aerodynamics parameters, which, of course, will increase its reliability and efficiency for conditions reducing of labor costs.

Secondly, if the control route is compelled to cover the sensor area UTAS - it will be possible to evaluate the effectiveness of both components of control and correct location of UTAS sensors in mining. Keep in mind the fact that the sensitivity and accuracy of measurements of aerodynamic parameters by modern means of control (see item 3 of paragraph 3) is comparable or much greater than the sensitiveness of UTAS sensors. 
Thus, the introduction of the proposed approach will allow for consideration advantages and eliminate the disadvantages of both components of the aerodynamic control system their parameters, reducing labor costs and contributing to increased security of miners. Apart, there will be an opportunity to optimize the amount of for necessary operation of the devices of stationary control aerodynamics- parameters (block 10 of Fig. 1), which, due to the limited production of it and the growth of the needs of mines is important.

5. Aerodynamic monitoring of ventilation during emergencies (block 11 Fig. 1) is a rather complicated problem due to the complexity of using existing devices in an emergency (it's hard to imagine the use of a pressure gauge with a rubber tube in a fire seat), and the implementation of operational control the aerodynamic state of the latter and especially isolated fire areas. The effectiveness of UTAS under these conditions is questionable, therefore monitoring with the use of modern control devices becomes essential.

6. The final, finished stage of evaluation and use of the results of the ADS is processing them using information and analytical technologies. These issues are devoted to several software products. This is, in particular, the most commonly used in Ukraine, developed by Naukovo-Doslidnyi Instytut Hirnychoriatuvalnoi Spravy ta Pozhezhnoi Bezpeky «Respirator» software complex "Ventilation of mines" [5], the RPPOD program [6], the program complex "IRS Ventilation-PLA" (development of Donetsk National Technical University [7], Russian complexes «Mine aerology (Ventilation)» [8] and "Air Network" [9]. However, the use of all of them successful causes in Ukraine is limited; moreover, they are not suitable for implementation of progressive approaches, described above. The most complete, which until then realizes the tasks of structural-parametric identification of the MVN, thus improving the use of the results of the ADS, is the development of IGTM NAS of Ukraine - Information and analytical technology of designing and spatial planning of coal mine ventilation systems "[10]. However, for more comprehensive coverage of the use of ADS results (as well as of course, and the results of the functioning of an integrated aerodynamic system control (see item 4 of paragraph 3 ) it requires some refinement. First of all It concerns the organization of a flexible graphical interface of the system, which is the most closer to our research.

\section{Conclusions}

The methods of structural and parametrical identification of mine ventilation network are developed, that enables to create its mathematical model, which, as a result of large degree of adequacy to the real network, can be effectively used during ventilation calculations. It is suggested to replace the out-of-date devices of control aerodynamic parameters by more modern, developed in IGTM NAS of Ukraine. As an interval between conducting of the $\mathrm{ADS}$ on a mine is very considerable, is offered new approach to actualization of information, that consists in complexing of measurings by the stationary and portable devices of control. Methods structurally - parametrical authentication and the measurable devices of monitoring of aerodynamic parameters of a new technical level are offered first. The use of the offered methods and hardwares of working of the ADS results will allow to promote quality of got aerodynamic information.

\section{References}

1. Bulat, A.F., Bunko, T.V., Yashchenko, I.A. et al. (2018). Sovershenstvovaniye funktsionirovaniya ugolnikh shakht: ventilyatsiya, konditsionirovaniye, degazatsiya, ekologiya. Dnipro: Zhurfond 
2. Bulat, A.F., Krukovsky, A.P., Bunko, T.V. et al. (2017). Otsenka opasnosti shakht s ispolzovaniyem teorii riskov, Geotechnical Mechanics, 135, 3-15

3. Bulat, A.F., Zvyagilsky, Ye.L., Bokiy, B.V. et al. (2006). Sovershenstvovaniye ventilyatsii $i$ degazatsii ugolnykh shakht. Dnepropetrovsk: Nord Computer

4. Radchenko, V.V., Maleyev, N.V., Martynov, A.A. et al. (2005). Perspectivy povysheniya urovnya promyshlennoy bezopasnosti ugolnykh shakht pri ispolzovanii sistemy dispetcherskogo kontrolya (UTAS), Gornyy informatsionno-analiticheskiy byulleten, 5, 31-43

5. Kravchenko, M.V., Kravchenko, N.V. (2003). Opyt vnedreniya programmnogo kompleksa «Ventilyatsiya shakht», Coal of Ukraine, 2, 26-28

6. Rukovodstvo po ekspluatatsii programmnoy sistemy REVOD. Versiya 4.2. (1999). Donetsk: Akademiya gornyih nauk Ukrainyi, Donbasskiy nauchnyiy tsentr

7. Trofimov, V.A., Romanchenko, S.B. (2005). Metodicheskiye ukazaniya po prakticheskim zanyatiyam "Modelirovaniye shakhtnykh ventilyatsionnykh setey». Donetsk: DNTU

8. Paleev, D.Yu., Lukashov, O.Yu. (2007). Programma rascheta ventilyatsionnykh rezhimov $v$ shakhtakh $i$ rudnikakh, Mining industry, 6, 20

9. Kazakov, B.P., Kruglov, Yu.V., Isayevich, A.G., Levin, L.Yu. (2006). Razrabotka programmno-vychislitelnogo kompleksa «AeroSet» dlya rascheta ventilyatsionnykh setey shakht i rudnikov, Gornyy informatsionno-analiticheskiy byulleten 10, 21-32

10. Poltavets, V.I., Bulat, A.F., Bunko, T.V. (2003). Ispolzovaniye kompyuternykh technologiy pri proyektirovanii ventilyatsii ugolnykh shakht. Lugansk-Dnipropetrovsk: Nord-Komputer 